\title{
Contamination of pigs by nose-to-nose contact or airborne transmission of Salmonella Typhimurium
}

\author{
Karine Proux*, Roland Cariolet, Philippe Fravalo, \\ Catherine Houdayer, André Keranflech, François Madec
}

AFSSA Ploufragan, BP 53, Zoopôle Beaucemaine, 22440 Ploufragan, France

(Received 1 February 2001; accepted 21 June 2001)

\begin{abstract}
The aim of this study is to assess the risk of contamination by Salmonella Typhimurium of pigs by nose-to-nose contact or the airborne route. Thirty twelve-week-old SPF pigs were divided into 4 groups housed in 4 different rooms: the first room contained Salmonella-free control pigs $(n=4)$, the second room had $10^{3} \mathrm{CFU} S$. Typhimurium inoculated pigs $(n=5)$ and non-inoculated "contact" pigs $(n=4)$, the third room had pigs $(n=8)$ receiving potentially contaminated air from the following room through a hole (4 pigs housed in the pen situated near the hole and 4 pigs in the pen at the opposite side of the room), and the fourth room had pigs $(n=5)$ inoculated with $10^{6} \mathrm{CFU}$ Salmonella Typhimurium and also non inoculated "contact" pigs $(n=4)$. The "contact" and the inoculated pigs were housed in adjacent pens allowing nose-to-nose contact. The 5 pigs orally inoculated with $10^{6} \mathrm{CFU} S$. Typhimurium were bacteriologically and serologically positive 1 week later and their environment was contaminated as early as 1 day pi. The faecal samples of 4 nose-to-nose contact pigs were bacteriologically positive and one of them was seropositive 5 weeks pi before the pigs were commingled. The 8 pigs housed in the third room received $S$. Typhimurium by an active airflow coming from the contaminated room $\left(1000 \mathrm{~m}^{3} /\right.$ hour $)$. Their faecal samples remained negative until 8 weeks pi but the environmental swabs taken in the room close to the airinlet were contaminated 2 days pi and positive swabs were found elsewhere in the room 5 weeks pi. Two seropositive pigs were encountered 8 weeks pi in the pen situated near the hole. Only one among the 5 pigs inoculated with $10^{3} \mathrm{CFU}$ had bacteriologically positive faeces 1 -week pi and the 4 pigs kept in noseto-nose contact with them remained negative. A dose of $10^{3} \mathrm{CFU}$ was too small to induce persistent excretion and to stimulate a humoral immune response. However, the dose of $10^{6} \mathrm{CFU}$ induced contamination of nose-to-nose contact pigs and contamination of the environment by airflow.
\end{abstract}

\section{ELISA / Salmonella / pig / airborne transmission}

Résumé - Contamination des porcs par contact nez-à-nez ou par voie aérienne par Salmonella Typhimurium. L'objectif de cette étude est d'évaluer le risque de contamination des porcs par contact nez-à-nez et par la voie aérienne. Trente porcs exempts d'organismes pathogènes spécifiques âgés de 12 semaines ont été subdivisés en 4 groupes hébergés dans 4 salles différentes : la

* Correspondence and reprints

Tel.: (33) 2960162 77; fax: (33) 2960162 63; e-mail: k.proux@ ploufragan.afssa.fr 
première salle contenant des porcs témoins indemnes de salmonelles $(n=4)$, la seconde salle des porcs $(n=5)$ inoculés avec $10^{3} \mathrm{~S}$. Typhimurium et des porcs « contacts » non-inoculés $(n=4)$, la troisième salle des porcs $(n=8)$ recevant de l'air potentiellement contaminé de la salle suivante au travers d'une bouche d'aération ( 4 porcs dans la case située près du trou et 4 porcs dans la case située à l'opposé), et la quatrième salle contenant des porcs $(n=5)$ inoculés avec $10^{6} \mathrm{~S}$. Typhimurium et aussi des porcs « contacts » non-inoculés $(n=4)$. Les porcs « contacts » et inoculés étaient hébergés dans des cases voisines permettant un contact nez-à-nez. Les 5 porcs inoculés par voie orale avec $10^{6} \mathrm{~S}$. Typhimurium étaient bactériologiquement et sérologiquement positifs 1 semaine plus tard et leur environnement était contaminé dès 1 semaine après inoculation. Les 4 porcs en contact nez-à-nez avaient des fèces bactériologiquement positives et l'un d'entre eux était séropositif avant mélange des porcs 5 semaines après inoculation. Les 8 porcs hébergés dans la troisième salle recevaient $S$. Typhimurium par un flux d'air actif de la salle contaminée $\left(1000 \mathrm{~m}^{3} /\right.$ heure). Leurs fèces sont demeurées négatives jusqu'à 8 semaines après inoculation mais les chiffonnettes d'environnement étaient contaminées 2 jours après inoculation sous le trou d'aération et les chiffonnettes étaient positives dans la salle entière 5 semaines après inoculation. Deux porcs se sont révélés séropositifs 8 semaines après inoculation dans la case située près de la bouche d'aération. Un seul porc parmi les 5 inoculés avec $10^{3}$ UFC avait des fèces bactériologiquement positives 1 semaine après inoculation et les 4 porcs en contact nez-à-nez avec eux sont restés négatifs. Une dose de $10^{3}$ UFC était trop faible pour induire une excrétion persistante et pour stimuler une réponse immunitaire humorale. Cependant une dose de $10^{6}$ UFC a induit une contamination des porcs en contact nez-à-nez et une contamination de l'environnement par le flux d'air.

\section{ELISA / Salmonella / porc / transmission aérienne}

\section{INTRODUCTION}

Although Salmonella infection occurs primarily by the oral route, the airborne route may also be relevant $[2,17]$. This route has been essentially studied in chickens by using artificial aerosols or natural crossinfection.

An experiment on the infection of chicks with an aerosol of $S$. Pullorum has been reported [3]. An airborne cross-infection by Salmonella Enteritidis phage type 4 (SE PT4) strains has already been demonstrated between sets of orally infected 1-d-old chicks and identical uninfected control chicks; low levels of airborne $S$. Enteritidis are a potential source of cross-infection [12]. Administration of aerosol doses of $10^{2}-10^{5}$ SE PT4 to hens induced intermittent excretion in faeces during 28 days post-inoculation. Moreover early infection in the lungs and crops and later systemic infection of the ovaries, oviducts, spleens, kidneys and eggs with SE-contaminated shells were observed [1]. This airborne route is relevant since Salmonella are able to survive within aerosols for long periods of time in quantities equivalent to those shown to produce systemic disease in chickens [13]. At an aerosol age of $90 \mathrm{~min}, S$. Typhimurium viability is about one percent of its initial value at all humidities [18].

In calves, Hinton et al. [11] described this natural airborne transmission showing that Salmonella infection appears randomly within a group of calves even if they are far from each other. This infection of calves with Salmonella by airborne transmission and the respiratory tract was studied further and proved by Wathes et al. [18].

In pigs, only the intranasal route of transmission has been described by Gray et al. [8] and Gray and Fedorka-Cray [9]. The aim of our study was to show nose-to-nose and airborne contamination in experimental conditions mimicking natural ones in order to use these results in the field area. If this contamination from pen to pen and from room to room is proved, measures will have to be conducted in order to protect Salmonellafree pigs from contaminated airflow. 


\section{MATERIALS AND METHODS}

\subsection{Salmonella strains and inoculations}

S. Hadar, Infantis and Anatum strains used to prepare the lipopolysaccharide antigens and $S$. Typhimurium used for inoculation of SPF (Specific Pathogen Free) pigs were isolated in the field from finishing pigs. Serovars were confirmed by the French Agency for Food Safety (AFSSA, Paris, France) which is the Salmonella reference laboratory for animal isolates.

Two doses were used for oral inoculation: $10^{3}$ CFU Salmonella Typhimurium since this was supposed to be the minimal dose inducing a contamination and $10^{6} \mathrm{CFU}$ because this dose induced infection but no diarrhea or clinical signs (not published results). Clinical signs and diarrhea were not wanted since under farm conditions, pigs are usually asymptomatic carriers and nose-to-nose contact were expected in this study. It was therefore necessary to reduce faecal projections as much as possible.

\subsection{Animals}

Thirty SPF pigs aged from 12-weeks-old were housed in 4 rooms: R1, R2, R3 and R4. Four non-inoculated pigs were kept as controls in the first room R1. In room R2, 5 pigs were orally inoculated at 12 weeks of age with $10^{3} \mathrm{CFU}$ of $S$. Typhimurium and 4 pigs were in nose-to-nose contact with them. In room R3, 8 pigs were reared in 2 pens in order to receive an airborne contamination by airflow through a hole drilled between this room and the following contaminated room R4. Four pigs were housed in pen R3A which was situated just in front of the hole whereas 4 pigs were in pen R3B opposite the hole. In the last room R4, 5 pigs were orally inoculated at 12 weeks of age with $10^{6} \mathrm{CFU}$ of $S$. Typhimurium, whereas 4 pigs were kept in a second pen in order to have nose-to-nose contact with the former ones.

\subsection{Experimental design}

In each room, 4 or 5 pigs were grouped in each pen; these pens were separated by $14 \mathrm{~cm}$. When inoculated pigs and nose-tonose contact pigs were housed in the same room, they were placed into separate pens. Faecal projections were at least partly inhibited by the use of raised pens, $60 \mathrm{~cm}$ high, allowing faeces elimination through the slatted flooring. Moreover the floors were cleaned daily, proceeding from the contact pen to the contaminated one. Animal attendants were obliged to feed and clean room $\mathrm{R} 1$ with the Salmonella-free pigs, then room R3 with the non-inoculated pigs in airborne contact, then room R2 containing $10^{3} \mathrm{~S}$. Typhimurium inoculated pigs and lastly room R4 with pigs inoculated with $10^{6} \mathrm{~S}$. Typhimurium. During the fifth week pi, inoculated and nose-to-nose contact pigs (R2 and R4), reared in two different pens from the same room were commingled in order to increase infection by stimulating fighting; 2 inoculated and 2 contact pigs were randomly distributed into each pen.

The hole between rooms R4 and R3 (respectively containing the pigs inoculated with $10^{6} \mathrm{CFU}$, and those in contact with the former ones by the airborne route) was drilled 1 day post-inoculation (pi). The hole (55 $\mathrm{cm}$ long and $20 \mathrm{~cm}$ large) was protected by a wooden panel in order to prevent direct contamination by projections. The airflow $\left(1000 \mathrm{~m}^{3} /\right.$ hour $)$ between these 2 rooms was produced by introducing air into the contaminated room R4 and extracting air from the non-contaminated room R3.

Pigs from R1 and R2 were slaughtered at 7 weeks pi. All pigs from R4 and R3 were kept respectively until 8 and 9 weeks pi, except 2 pigs ( 1 inoculated with $10^{3} \mathrm{CFU}$ and 1 inoculated with $10^{6} \mathrm{CFU}$ ) which were killed 4 weeks pi in order to reduce density.

\subsection{Samples}

Sera and faeces were collected each week respectively until 9 and 8 weeks pi. During 
the fifth week pi, sera and faeces were collected respectively 1 and 2 days before the pigs were commingled.

Environmental swabs were sampled just under the hole in the contact room R3: 1 day pi (one swab collected just after the hole was drilled and another one when the dynamic airflow was processed), 2 days pi ( 2 swabs) and each week until 6 weeks pi (1 swab per week). Swabs were also collected from each pen and from the floor and walls around each pen at 4, 5 (1 day after the pigs were commingled in order to allow the mouth-to-mouth contact) and 6 weeks pi in order to show the spread of Salmonella between inoculated and contact pigs induced by mouth-to-mouth contact at 5 weeks pi. Swabs were also used 2, 10 and 16 days pi to detect Salmonella on the air filter in room R3 containing air contact pigs. Moreover, plate count agars were put in an air collector (Aerobio collector BIOBLOCK, Illkirch, France), in order to test the air just under the hole between the contaminated room R4 and $\mathrm{R} 3$ at 1,2 and 4 days pi $(840 \mathrm{~L}$ that is $0.840 \mathrm{~m}^{3}$ of air at least were tested per day in $5 \mathrm{~min}$ ). Pigs were finally checked bacteriologically and serologically at slaughter for Salmonella: approximately $10 \mathrm{~g}$ of stomach contents and $10 \mathrm{~g}$ of contents from the ileum, caecum and rectum were extracted aseptically. In addition the tonsils, one mesenteric lymph node from the small intestine, the ileo-caecal lymph node and the sera obtained just after bleeding were tested. All these samples were processed individually.

\subsection{Bacteriological examination}

Samples were diluted in buffered peptone water $(1: 10$ dilution $\mathrm{w} / \mathrm{v})$ and were incubated for 16 to $20 \mathrm{~h}$ at $37^{\circ} \mathrm{C}$. The enrichment step used semi-solid Rappaport Vassiliadis (RV) medium (Biokar Diagnostic, Beauvais, France) incubated for $24 \mathrm{~h}$ (and $24 \mathrm{~h}$ more if necessary) at $41.5^{\circ} \mathrm{C}$ or Müller-Kaufmann broth (MK-Armor Equip. Scientific Lab., Combourg, France) incu- bated for $24 \mathrm{~h}$ at $42{ }^{\circ} \mathrm{C}$. Presumptive positive results obtained on semi-solid RV and indicated by migration were sub-cultured onto Rambach agar (Merck, Nogent-sur-Marne, France) whereas samples enriched on MK were isolated on Xylose-Lysine-Tergitol 4 agar (XLT4-Difco Laboratories, Detroit, MI 48232-7058, USA); agars were incubated at $37^{\circ} \mathrm{C}$ for $24 \mathrm{~h}$ and $24 \mathrm{~h}$ more if necessary. One crimson and one black colony, respectively isolated from the Rambach and XLT4 agars were confirmed biochemically and serotyped using appropriate poly- and monovalent typing sera (Sanofi-Diagnostic Pasteur, Marnes-LaCoquette, France).

\subsection{ELISA}

The sera were tested with the complete ELISA described previously by Proux et al. [16] which was based on LPS from $S$. Typhimurium, Enteritidis, Anatum, Hadar and Infantis. To eliminate the background caused by reaction with the diluents, a corrected optical density (OD) equal to the difference between the optical density with the positive and the control without antigen was calculated for each sample. The background OD with the negative sera was corrected by the following calculation of R equal to: (OD sample-OD negative control)/(OD positive control-OD negative control). The calibrated optical density (COD) was then calculated as: R X (mean OD positive control / OD positive control on the plate). The mean OD positive control value was established on 50 different plates for the positive control and was equal to 1 . The positive cut-off was established at 0.4 .

\subsection{Statistical analysis}

Bacteriological results on organs and digestive tract contents of inoculated and contact pigs were compared with a Pearson test. All the serological results were 
compared using analysis of variance (ANOVA test) for repeated and correlated series since the response observed one week depended on the others.

\section{RESULTS}

\subsection{Bacteriological results}

\subsubsection{Environmental samples}

In room $\mathrm{R} 1$ containing control pigs, the swabs remained negative as did those from room R2 containing pigs inoculated with $10^{3}$ CFU $S$. Typhimurium. In room R3, the swab collected under the hole receiving contaminated air from room R4 (containing pigs inoculated with $10^{6}$ CFU $S$. Typhimurium) was positive 2 days pi, that is 1 day after the hole was drilled and the dynamic airflow was instituted. The swab collected at the same place was positive intermittently until the end of the experiment 34 days pi (Tab. I). On the contrary, the swabs collected on the air filter and plate count agars put in the air collector remained negative until the end of the experiment.

Only the pen R4A containing pigs inoculated with $10^{6} \mathrm{CFU} S$. Typhimurium was positive until 4 weeks pi. Then, all the swabs collected in room R4 (i.e., 2 pens and 2 floors around the pens) were positive whatever the pen considered, 5 weeks pi, 1 day after the inoculated and nose-to-nose contact pigs were commingled. Both pens and floors in room $\mathrm{R} 3$ receiving contaminated air were positive 5 weeks pi. One week later, room R4 remained positive (i.e., 2 pens and 2 floors around the pens) whereas in room R3 only the pen situated near the hole was still contaminated although the floors around them were all positive (Tab. II).

\subsubsection{Faecal samples (Tab. III)}

The faecal samples collected from the control pigs remained negative.

Concerning the inoculated pigs, only 1 of the 5 pigs inoculated with $10^{3} \mathrm{CFU}$ shedded Salmonella Typhimurium 1 week pi whereas the 5 pigs inoculated with $10^{6} \mathrm{CFU}$ had positive faecal samples from 1 week after inoculation on.

One pig became contaminated 1 week after the nose-to-nose contact with the pigs inoculated with $10^{6} \mathrm{CFU}$, and all these contact pigs excreted Salmonella 5 weeks pi, i.e. before they were commingled with the inoculated pigs.

Table I. Bacteriological results of environmental swabs sampled under the hole between room R3 and R4 containing pigs inoculated with $10^{6}$ CFU Salmonella Typhimurium.

\begin{tabular}{lcc}
\hline Week after infection & Days post infection & Positive / total no. of swabs \\
\hline 0 & $1^{\mathrm{a}}$ & $0 / 1$ \\
0 & $1^{\mathrm{b}}$ & $0 / 1$ \\
0 & 2 & $1 / 2$ \\
1 & 4 & $1 / 1$ \\
2 & 10 & $1 / 1$ \\
3 & 16 & $0 / 1$ \\
4 & 22 & $0 / 1$ \\
5 & 31 & $1 / 1$ \\
6 & 34 & $1 / 1$ \\
\hline
\end{tabular}

a Opening of the hole.

${ }^{\mathrm{b}}$ Dynamic air flow put on. 
Table II. Positive bacteriological results on two environmental swabs (one collected in each pen and one on the floors and the walls).

\begin{tabular}{|c|c|c|c|c|c|c|c|}
\hline \multirow{3}{*}{$\begin{array}{l}\text { Week after } \\
\text { infection }\end{array}$} & \multicolumn{7}{|c|}{ Rooms and pens } \\
\hline & \multirow{2}{*}{$\begin{array}{c}\text { R1 } \\
\text { Controls }\end{array}$} & \multicolumn{2}{|c|}{$\mathrm{R} 2$} & \multicolumn{2}{|c|}{ R3 } & \multicolumn{2}{|c|}{$\mathrm{R} 4$} \\
\hline & & $\begin{array}{c}\mathrm{A} \\
\text { Inoculated } \\
10^{3}\end{array}$ & $\underset{\text { Contact }}{\mathrm{B}}$ & $\begin{array}{c}\text { A } \\
\text { Airborne } \\
\text { contact }^{c}\end{array}$ & $\begin{array}{c}\text { B } \\
\text { Airborne } \\
\text { contact } d\end{array}$ & $\begin{array}{c}\mathrm{A} \\
\text { Inoculated } \\
10^{6}\end{array}$ & $\underset{\text { Contact }^{b}}{\mathrm{~b}}$ \\
\hline 4 & 0 & 0 & 0 & 0 & 0 & 1 (pen) & 0 \\
\hline $5^{\mathrm{a}}$ & 0 & 0 & 0 & 2 & 2 & 2 & 2 \\
\hline 6 & 0 & 0 & 0 & 2 & 1(floor) & 2 & 2 \\
\hline
\end{tabular}

${ }^{\text {a }}$ One day after the pigs were commingled in rooms R2 and R4.

${ }^{\mathrm{b}}$ Nose-to-nose contact until 5 weeks pi and mouth-to-mouth contact until the end of the experiment.

${ }^{c}$ Pen in airborne contact with pigs inoculated with $10^{6} \mathrm{CFU}$, situated near the hole.

${ }^{\mathrm{d}} \mathrm{Pen}$ in airborne contact with pigs inoculated with $10^{6} \mathrm{CFU}$, situated opposite the hole.

Table III. Positive bacteriological results on faecal samples.

\begin{tabular}{|c|c|c|c|c|c|c|c|}
\hline \multirow{3}{*}{$\begin{array}{l}\text { Week after } \\
\text { infection }\end{array}$} & \multicolumn{7}{|c|}{ Rooms and pens } \\
\hline & \multirow{2}{*}{$\begin{array}{c}\mathrm{R} 1 \\
\text { Controls } \\
\text { (4) }\end{array}$} & \multicolumn{2}{|c|}{$\mathrm{R} 2$} & \multicolumn{2}{|c|}{$\mathrm{R} 3$} & \multicolumn{2}{|c|}{$\mathrm{R} 4$} \\
\hline & & $\begin{array}{c}\text { A } \\
\text { Inoculated } \\
10^{3} \\
(5)^{b}\end{array}$ & $\begin{array}{c}\text { B } \\
\text { Contact }^{c} \\
\text { (4) }\end{array}$ & $\begin{array}{c}\text { A } \\
\text { Airborne } \\
\text { contact d }^{\mathrm{d}} \\
\text { (4) }\end{array}$ & $\begin{array}{c}\text { B } \\
\text { Airborne } \\
\text { contact }^{\mathrm{e}} \\
\text { (4) }\end{array}$ & $\begin{array}{c}\text { A } \\
\text { Inoculated } \\
10^{6} \\
(5)^{\mathrm{b}}\end{array}$ & $\begin{array}{c}\text { B } \\
\text { Contact }^{c} \\
\text { (4) }\end{array}$ \\
\hline 0 & 0 & 0 & 0 & 0 & 0 & 5 & 0 \\
\hline 1 & 0 & 1 & 0 & 0 & 0 & 5 & 1 \\
\hline 2 & 0 & 0 & 0 & 0 & 0 & 5 & 0 \\
\hline 3 & 0 & 0 & 0 & 0 & 0 & 5 & 0 \\
\hline 4 & 0 & 0 & 0 & 0 & 0 & 5 & 0 \\
\hline $5^{a}$ & 0 & 0 & 0 & 0 & 0 & 4 & 4 \\
\hline 6 & 0 & 0 & 0 & 0 & 0 & 4 & 4 \\
\hline 7 & 0 & 0 & 0 & 0 & 0 & 4 & 4 \\
\hline 8 & & & & 0 & 0 & & \\
\hline
\end{tabular}

${ }^{a}$ Faeces sampled 2 days before the pigs were commingled in rooms R2 and R4.

${ }^{\mathrm{b}}$ One pig killed 4 weeks pi.

${ }^{c}$ Nose-to-nose contact until 5 weeks pi and mouth-to-mouth contact until the end of the experiment.

${ }^{\mathrm{d}}$ Pen in airborne contact with pigs inoculated with $10^{6} \mathrm{CFU}$, situated near the hole.

e Pen in airborne contact with pigs inoculated with $10^{6} \mathrm{CFU}$, situated opposite the hole.

In room R3, the pigs kept in airborne contact with the pigs inoculated with $10^{6} \mathrm{CFU}$ remained negative.

\subsubsection{Organs and digestive tract contents}

According to our bacteriological analysis on organs, only the pigs inoculated with
$10^{6} \mathrm{CFU}$ and the contact pigs housed in room R4 were all positive (Tab. IV). The tonsils, ileal, caecal and rectal faeces of the pigs inoculated with $10^{6} \mathrm{CFU}$ were all positive whereas some of the stomach contents, mesenteric and ileo-caecal lymph nodes were positive with 1,2 and 2 respectively. 
Table IV. Positive bacteriological results of organs, stomach and intestinal contents when the pigs were sacrificed (8 weeks after inoculation).

\begin{tabular}{|c|c|c|c|c|c|c|c|}
\hline \multirow{3}{*}{ Sample } & \multicolumn{7}{|c|}{ Rooms and pens } \\
\hline & \multirow{2}{*}{$\begin{array}{c}\text { R1 } \\
\text { Controls }\end{array}$} & \multicolumn{2}{|c|}{$\mathrm{R} 2$} & \multicolumn{2}{|c|}{ R3 } & \multicolumn{2}{|c|}{$\mathrm{R} 4$} \\
\hline & & $\begin{array}{c}\text { A } \\
\text { Inoculated } \\
10^{3} \\
(5)^{\mathrm{a}}\end{array}$ & $\begin{array}{c}\text { B } \\
\text { Contact } b \\
\text { (4) }\end{array}$ & $\begin{array}{c}\text { A } \\
\text { Airborne } \\
\text { contact }{ }^{\mathrm{c}} \\
\text { (4) }\end{array}$ & $\begin{array}{c}\text { B } \\
\text { Airborne } \\
\text { contact } d \\
\text { (4) }\end{array}$ & $\begin{array}{c}\text { A } \\
\text { Inoculated } \\
10^{6} \\
(5)^{\mathrm{a}}\end{array}$ & $\begin{array}{c}\text { B } \\
\text { Contact } \\
\text { (4) }\end{array}$ \\
\hline Tonsils & 0 & 0 & 0 & 0 & 0 & 5 & 4 \\
\hline Stomach content & it 0 & 0 & 0 & 0 & 0 & 1 & 2 \\
\hline Ileal faeces & 0 & 0 & 0 & 0 & 0 & $4^{e}$ & 3 \\
\hline Caecal faeces & 0 & 0 & 0 & 0 & 0 & 5 & 4 \\
\hline Rectal faeces & 0 & 0 & 0 & 0 & 0 & $4^{e}$ & 3 \\
\hline Mesenteric & 0 & 0 & 0 & 0 & 0 & 2 & 3 \\
\hline $\begin{array}{l}\text { Ileo-caecal } \\
\text { Lymph node }\end{array}$ & 0 & 0 & 0 & 0 & 0 & 2 & 3 \\
\hline Positive animal & 0 & 0 & 0 & 0 & 0 & 5 & 4 \\
\hline
\end{tabular}

a One pig killed 4 weeks pi.

${ }^{\mathrm{b}}$ Nose-to-nose contact until 5 weeks pi and mouth-to-mouth contact until 8 weeks pi.

${ }^{c}$ Pen in airborne contact with pigs inoculated with $10^{6} \mathrm{CFU}$, situated near the hole.

${ }^{\mathrm{d}}$ Pen in airborne contact with pigs inoculated with $10^{6} \mathrm{CFU}$, situated opposite the hole.

e Sample not tested on 1 pig.

All tonsils and caecal faeces of the contact pigs reared in the same room were positive and some of the other samples were positive. According to the Pearson test, the bacteriological results were significantly different $(p<0.05)$ on pigs inoculated with $10^{6} \mathrm{CFU}$ and the contact pigs housed in room R4.

\subsection{Serological results}

The mean calibrated optical density (MCOD) was high on the $10^{6} \mathrm{CFU}$ inoculated pigs, as early as 1 week pi $(\mathrm{MCOD}=1.426)$, and almost all these pigs were seropositive from 1 to 9 weeks after inoculation (Fig. 1). One close contact pig $(25 \%)$ was seropositive $(\mathrm{MCOD}=0.127)$ 5 weeks pi, that is before the pigs were commingled. Then, $100 \%$ of the pigs were seropositive $(\mathrm{MCOD}=1.882) 6$ weeks after inoculation, that is 1 week after being mixed with the inoculated pigs (Fig. 1). The MCOD increased on airborne contact pigs housed in room R3, 8 weeks pi (from 0 to 0.244 in pen R3A and to 0.270 in pen R3B). Moreover, in pen R3A situated near the hole, 2 pigs $(50 \%)$ were seropositive 8 weeks after inoculation (Fig. 1).

On the contrary, the pigs inoculated with $10^{3} \mathrm{CFU}$ and the contact pigs housed in room R2 remained seronegative until 7 weeks pi. Finally, the MCOD on control pigs stayed close to zero until the end of the experiment.

The serological results were significantly $(p<0.05)$ different when all the groups were considered from 1 to 9 weeks pi. No differences were observed from 1 to 5 weeks pi between the pigs kept in nose-to-nose contact and the pigs in airborne contact with those inoculated with $10^{6} \mathrm{CFU}$ $S$. Typhimurium. However the results obtained from 6 to 9 weeks pi were 


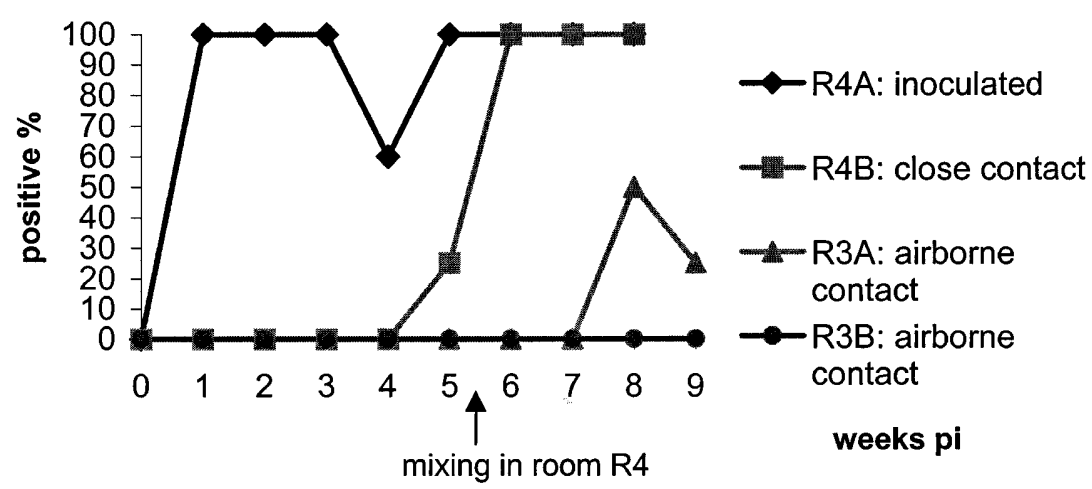

Figure 1. Seropositive percentage of pigs: inoculated with $10^{6}$ Salmonella Typhimurium (pen R4A), pigs in close contact with the former pigs and housed in the same room (pen R4B) and pigs in airborne contact housed in another room (pen R3A situated near the hole between room R4 and R3, pen R3B situated opposite the hole).

significantly $(p<0.05)$ different for pigs in mouth-to-mouth contact and pigs in airborne contact. These serological results were not, however, significantly different from 6 to 9 weeks pi for pigs inoculated with $10^{6} \mathrm{CFU}$ and the pigs kept in mouth-to-mouth contact with them. In room $\mathrm{R} 3$, which received contaminated air, the results were not significantly different, whatever the pen considered.

\section{DISCUSSION}

The objective of the study was to determine the efficiency of nose-to-nose and airborne contamination by $S$. Typhimurium. Previously, only experimental inoculations (intranasal route) which differ from farm conditions, were realised in pigs by Gray et al. [8] and Gray and Fedorka-Cray [9]. In our experiment, two routes were used: nose-to-nose contact which does not completely exclude aerosols generated by defaecation from one pen to the adjacent one and airborne contamination from one room to another one receiving Salmonella by a dynamic airflow.
The nose-to-nose route seems to be efficient since faecal contamination of all contact pigs was shown 5 weeks after oral inoculation of the adjacent pigs with $10^{6} \mathrm{CFU}$ $S$. Typhimurium. This contamination was confirmed by the serological results since 1 nose-to-nose contact pig was seropositive at the same moment. In addition, 1 nose-tonose contact pig was already excreting Salmonella 1 week pi and even if animal handlers were really cautious the chance of human spread of the bacteria was still a possibility. The spread of Salmonella Typhimurium by the airborne route was shown since room R3 was contaminated 2 days pi but the contamination of the pigs housed in this room was not observed according to the bacteriological analysis of faecal samples. Under the farming conditions used in our study, high sanitary measures may reduce the persistence and the number of Salmonella. The floor and pens were daily cleaned and washed and this eliminates particles in which Salmonella usually live in a conventional farm. The study was limited to 8 weeks pi; it might, however, have been necessary to keep the pigs longer in this contaminated area to try 
to have them infected. Nevertheless, 2 seropositive pigs were encountered among these 8 contact pigs 8 weeks pi; these contaminated pigs were situated in the pen just in front of the hole conducting the air carrying Salmonella and contaminating the environment.

Our results suggest that the natural airborne route induces a humoral immune response. A serological response was also obtained by Chart et al. [2] using an aerosol challenge. Moreover, as it is generally admitted, serology appears to be more sensitive than bacteriology [15]. This shows the interest of using serology to detect carrier pigs who remain negative with a routine bacteriological analysis.

Digestive tract and tonsils were really susceptible and would be useful in further screening at the slaughterhouse to show the bacteriological contamination of pigs. On the contrary, lymph nodes were not so susceptible since only some were positive in pigs inoculated with $10^{6} \mathrm{CFU}$ $S$. Typhimurium.

Moreover agars collected on the air filter were entirely negative and we may conclude that the particles adsorbed there were too small to transport Salmonella, or our method was inefficient at showing a low contamination of the air. Even though $2520 \mathrm{~L}$ that is $2.52 \mathrm{~m}^{3}$ of air were controlled, we suggest that it is necessary to test a higher air volume.

MacDermid and Lever [13] have shown that Salmonella may be carried on dust particles or in airborne droplets. Davies and Wray [5] concluded that in commercial broiler hatcheries, Salmonella contamination could be reduced most effectively by minimising dust, fluff and aerosol production. On a pig farm, the decrease of dust may also be relevant in reducing the contamination of the airflow from a pen to a non-adjacent pen or from a room to an other one. Moreover dust samples may harbour Salmonella long after the houses are depopulated [6], even after cleaning and disinfec- tion [10]. In addition for Dahl et al. [4], cleaning with high pressure hosing requires empty sections in order to avoid spread of Salmonella by aerosols to naive pigs. Nakamura et al. [14] decreased the horizontal spread of Salmonella along a row of caged chickens by airflow in the opposite direction. Gast et al. [7] used negative air ionisation to reduce levels of circulating airborne dust particles by attracting them to grounded surfaces. Further studies should be focused on the different methods aiming at reducing the risks of Salmonella contamination of pig facilities at the farm level.

\section{ACKNOWLEDGEMENTS}

This work was supported by the French Food Safety Agency. The authors are grateful to the staff for taking care of the pigs.

\section{REFERENCES}

[1] Baskerville A., Humphrey T.J., Fitzgeorge R.B., Cook R.W., Chart H., Rowe B., Whitehead A., Airborne infection of laying hens with Salmonella enteritidis phage-type 4, Vet. Rec. 130 (1992) 395-398.

[2] Chart H., Baskerville A., Humphrey T.J., Rowe B., Serological responses of chickens experimentally infected with Salmonella Enteritidis PT4 by different routes, Epidemiol. Infect. 109 (1992), 297-302.

[3] Clemmer D.I., Hickey J.L.S., Bridges J.F., Schliessman D.J., Shaffer M. F., Bacteriologic studies of experimental air-borne salmonellosis in chicks, J. Infect. Dis., 106 (1960) 197-210.

[4] Dahl J., Wingstrand A., Baggesen D.L., Nielsen B., Elimination of Salmonella Typhimurium infection by the strategic movement of pigs, Vet. Rec. 140 (1997) 679-681.

[5] Davies R.H., Wray C., An approach to reduction of Salmonella infection in broiler chicken flocks through intensive sampling and identification of cross-contamination hazards in commercial hatcheries, Int. J. Food Microbiol. 24 (1994) 147160.

[6] Davies R.H., Wray C., Persistence of Salmonella Enteritidis in poultry units and poultry food, $\mathrm{Br}$. Poult. Sci., 37 (1996) 589-596.

[7] Gast R.K., Mitchell B.W., Holt P.S., Application of negative air ionisation for reducing experimental airborne transmission of Salmonella Enteritidis to chicks, Poult. Sci., 78 (1999) 57-61. 
[8] Gray J.T., Fedorka-Cray P.J., Stabel T.J., Ackermann M.R., Influence of inoculation route on the carrier state of Salmonella Choleraesuis in swine. Vet. Microbiol. 47 (1995) 43-59.

[9] Gray J.T., Fedorka-Cray P.J., Detection of swine exposed to Salmonella. Proceedings of the Third International Symposium on Epidemiology and Control of Salmonella in Pork, Washington, DC, USA, August 5-7, 1999, 46-50.

[10] Higgins R., Malo R., René-Roberge E., Gauthier R., Studies on the dissemination of Salmonella in nine broiler-chicken flocks, Avian Dis., 26 (1982) 26-33.

[11] Hinton M., Ali E.A., Allen V., Linton A.H., The excretion of Salmonella Typhimurium in the faeces of calves fed milk substitute, J. Hyg. 91 (1983) $33-45$.

[12] Lever M.S., Williams A., Cross-infection of chicks by airborne transmission of Salmonella Enteritidis PT4, Lett. Appl. Microbiol. 23 (1996) 347-349.

[13] MacDermid A., Lever M.S., Survival of Salmonella Enteritidis PT4 and S. Typhimurium
Swindon in aerosols, Lett. Appl. Microbiol. 23 (1996) 107-109.

[14] Nakamura M., Takagi M., Takahashi T., Suzuki S., Sato S., Takehara K., The effect of the flow of air on horizontal transmission of Salmonella Enteritidis in chickens, Avian Dis. 41 (1997) 354360.

[15] Proux K., Humbert F., Guittet M., Bennejean G., Dépistage sérologique des salmonelloses aviaires à $S$. Enteritidis, Proceedings 1ères Journées de la Recherche Avicole, Angers, France, 28-29-30 Mars, 1995, 215-217.

[16] Proux K., Houdayer C., Humbert F., Cariolet R., Rose V., Eveno E., Madec F., Development of a complete ELISA using Salmonella lipopolysaccharides of various serogroups allowing to detect all infected pigs, Vet. Res. 31 (2000) 481-490.

[17] Tannock G.W., Smith J.M.B., A Salmonella carrier state involving the upper respiratory tract of mice, J. Infect. Dis. 123 (1971) 502-506.

[18] Wathes C.M., Zaidan W.A.R., Pearson G.R., Hinton M., Todd N., Aerosol infection of calves and mice with Salmonella Typhimurium, Vet. Rec. 123 (1988) 590-594. 